\title{
V: WRITERS AND SPEAKeRS: PSEUdONYMOUS INTELLIGENTSIA ANd ANonymous People
}

Without a faith-justified or not-in self-organized publics, organically linked to our activity in their very existence, capable of being addressed, and capable of action, we would be nothing but the peasants of capital. (Warner 2002, 52)

Warner casually uses the word "peasant" to describe one (under the conditions of modern global capitalism) who cannot imagine a selforganized public. The Georgian intelligentsia would surely have agreed: the word "peasant" denoted precisely the sort of person who was not a member of the public. In the post-Emancipation social imaginary, the unenlightened people ( $x a l x i$, identified with the rural peasantry) and enlightened society or public (sazogadoeba, the urbanizing aristocracy and intelligentsia) were imagined as almost diametrical opposites. It was precisely this gap between "the people" and "the public" that the intelligentsia saw as their historic role to overcome through projects like the spread of literacy, but generally speaking, in the meantime, the voices of the people could only enter the public and be known by acts of transcription. Until such time as the invidious distinction between the people (the rural peasantry) and the public (the urban intelligentsia) could be abolished by propagation of literacy, the intelligentsia could come to know (gacnoba) the estranged people by describing their lives and by transcribing their voices.

Warner's offhand comment seizes on "peasants" as a term for the benighted denizens of an imaginary Orientalist or capitalist "anti-public" which stands in handy opposition to the enlightened "people" of a liberal Occidentalist public. But by doing so, Warner, inadvertently perhaps, illustrates a basic structural difference between how Western publics and what we could call Eastern European "intelligentsia publics" are imagined, allowing us a critical vantage point for more precisely characterizing the differences between the Western liberal model of public and its abject Eastern other. Central to understanding these differences will 
be devices of inscription (pseudonyms), by which the intelligentsia constitute themselves as members of a "public" understood to consist not so much of Andersonian readers as writers, and devices of transcription, by which the intelligentsia constitute "the people" as peasants, those who cannot be addressed by public discourse and can only speak in print through a mediating act of transcription.

The peasant was indeed a very rare guest among the correspondents to Droeba. Around the same period that Ilia Chavchavadze finally completed his Letters of a Traveler (1871), we find an unusual letter to Droeba entitled "the rules of burying the dead in Imereti." ${ }^{1}$ There is nothing particularly unusual about the title or content of the letter, which is an utterly commonplace attack on a "harmful and impoverishing custom" typical of the backwardness of West Georgia, specifically the crippling expenses related to funeral feasts. Letters describing such "harmful and impoverishing customs" form a mainstay of local correspondence to Droeba throughout the period. Rather, it is the authorship of the letter that makes it unusual. The author signs himself "A temporarily obligated peasant from Kulashi" (erti kulasheli valdebuli glexi) and introduces himself deferentially to the Lord Editor [upalo redaktoro, the correct form of address for an editor] as at best a marginal participant of print culture:

I hope, Lord Editor, that you will not scorn printing an article received from a peasant man in your respected newspaper. $^{2}$

The peasant writer seems familiar enough with the norms of print culture to know that he, as a peasant, is an outsider. Certainly, the print culture of Droeba assumes a certain kind of person as the normal writer and reader, centering on a male urban member of the aristocracy or emergent intelligentsia. Letters from peasants or women are rare enough to elicit special editorial comment or special treatment throughout the period. For example, female writers, like peasants, are a relative rarity, and thus tend to elicit special editorial comment. To a letter written in 1869 in a somewhat archaic and stilted style from Germany, the editor appends a half-apologetic, patronizing footnote:

*) This article is a response to our own article and as the reader can see, belongs to a woman's pen, with which 
she represents to us her own ideas, which she has gotten from reading our article. We hope that our public will be satisfied with this article and will encourage our women, who increasingly pursue reading (more than men), to occasionally inform 'Droeba' of their own ideas. . . . Editors $^{3}$

What is strange about the letter from the peasant of 1872 is, first of all, how familiar this peasant outsider is with the conventions of print culture correspondence, including the proper way to address an editor, or the use of a pseudonym, so much so that he deferentially anticipates a possible objection to printing a letter from an outsider like himself.

To show how familiar this peasant is with the norms of print culture, let us look at another letter from a peasant describing the grievances of the mountain-dwelling Xevsurs. This peasant writer signs himself with what appears to be his real name, Imeda Kistauri of the village Ghuli, and writes in (or is transcribed in) an extremely strong Xevsur dialect with little or no sign of familiarity with standard Georgian, spoken or written. He does not even appear to be aware that there is a difference as addressees between the public of Droeba and the state! Unlike the other peasant letter writer, Imeda Kistauri lacks any self-consciousness about his own marginality, and also seems to be ignorant in every last detail of any of the conventions or devices of literate correspondence. Unlike "the peasant from Kulashi," Imeda Kistauri of Ghuli neither uses a pseudonym for himself, nor does he know how to properly address the editor (whom he addresses as Mr. Newspaperman [batono megazete]). The letter is so clearly alien to the print culture of Droeba that the editor makes no attempt to adapt it to the conventions of print, instead signaling its otherness with a footnote stating, "*) We print this with language unchanged."

The peasant from Kulashi, who is clearly not the complete outsider that Imeda Kistauri is, anticipates a further question about the identity of the author. Or rather, since this is a letter from a peasant, two questions: Who is the author, the "peasant from Kulashi," and since peasants are by definition illiterate, who is the writer?

Perhaps, you would wonder: who is this 'Peasant from Kulashi' and who is the writer of the articles? That is true, I neither know how to write nor to read, but I am having 
someone who knows writing write with my words. ${ }^{5}$

This peasant is aware that the identity of "peasant" implies that the role of author must be divided into a speaker and a transcriber. If the answer to the first question ("who is the speaker?") is "a peasant," the answer to the follow-up question ("who is the transcriber?") is, of course, "an aristocrat." If peasants are all illiterate, it follows that writers are primarily aristocrats, and transcription is not innocent of relations of power between the aristocratic writer and the peasant speaker, particularly for a newly emancipated serf who is still temporarily obligated to his former lord. Here, for example, having explained the conditions of possibility of this letter as an act of transcription, the peasant correspondent goes on to describe the suffering caused even among the wealthy aristocrats by the crippling costs of funeral customs, the rapacity of village priests, and so on. But just as he is about to describe the even greater suffering caused by these harmful and expensive customs among the impoverished peasantry, his narrative cuts short, because his transcriber, himself a nobleman, has apparently become angry at the words he is transcribing, critical as they are of his own estate, flung his pen down, and stormed off:

With great contentment I would have told you about these things, but my secretary is of high rank, and . . . flung the pen from his hand and told me angrily: 'It is indeed not a lie what they say about peasants: "If you seat a peasant by your side, he demands to be treated like an in-law," he stopped writing and left me angrily, until I should find [someone else] accept this and when I have found one, then I will describe to you. ... ${ }^{6}$

While the peasant from Kulashi is initially quite forthcoming about how his letter was transcribed, at the end of the letter, we are not at all clear how this moment of scribal rebellion was itself transcribed. Just as we begin to wonder about this, we also begin to wonder how what purports to be a transcription of the speech of an illiterate peasant comes to be accompanied by such writerly devices as footnotes (including footnotes that gloss terms unfamiliar to the reader of Droeba, along with those that contain other local knowledge), more or less as Chavchavadze 
used footnotes to render the dialogue with Ghunia as a folkloric text. ${ }^{7}$ At this point, we may well wonder if the we should be asking not "Who is the speaking peasant, and who is the writer?," but rather, "Who is the writer hiding under the guise of transcription of the voice of a peasant?"

As the peasant from Kulashi notes, transcription makes authorial identity into a nonidentity, the question of authorial identity becomes two separate questions. Since the peasant uses an obvious pseudonym ("Peasant from Kulashi") rather than a proper name (like Imeda Kistauri), there is the question raised by any obvious pseudonym: Who is this Peasant from Kulashi? And since he is a peasant from Kulashi and can, by definition, only be the creator of the spoken words, a second question arises of how these words came to be written: Who is the writer transcribing them onto the page? These two kinds of questions, one relating to the authorial figure created by technologies of inscription, by literary devices like the pseudonym "Peasant from Kulashi," and the other to the authorial figure created by technologies of transcription that turn "living" speaking voices into words on a page, then, form the material for this chapter. ${ }^{8}$ Both technologies create an opposition between an embodied, flesh-and-blood self-identical speaking subject, what I will call, following Goffman, a "natural figure," a figure which "stands for itself" (Goffman 1974: 524-5), bundled with all manner of individuating particularities, linguistic and material, verbal, bodily, and sartorial, embodied status attributes, what we might call "qualities of presence," and a disembodied "printed figure" with considerably diminished qualities of presence (and virtually all of a linguistic order) (Goffman 1974, 529).

However, while both of these devices create a gap between a natural and a textual figure, the pseudonym emphasizes this gap; transcription seeks to minimize it (I am borrowing here from the conceptualization of intertextual gaps presented by Bauman 2004). Pseudonyms create an anonymous universe of liberal strangers, unencumbered by their embodied status attributes, while transcriptions create a universe of Orientalist strangers; its technologies are designed to convey the embodied strangeness of the voice of the other. The device of the pseudonym produces a disembodied figure of a writer, an intelligentsia member of a public. It functions, for the most part, to establish and maintain a gap between the natural figure and the printed figure which in fact constitutes the writer as a writer; the authentic presence of the embodied natural figure is effaced and replaced by a printed figure that 
makes no pretense of being a natural figure, the writer begins where the speaker ends. If anything, what is displayed by the pseudonym, like the theatrical mask, is the nonidentity of author and actor, what Goffman calls a "staged figure" (Goffman 1974, 523-4), only here it is a print version of a staged figure.

The device of transcription also creates a printed figure, but more specifically what Goffman calls a "cited figure," a figure within quotation marks (Goffman 1974, 529). Here too there is a nonidentity between the writer and the speaker: the former a mere transcriber, the latter the author and principal of the words. The transcribed speaker is almost always an illiterate peasant (as a transcribed voice) and the technologies of transcription are devoted, for the most part, to reestablishing the qualities of presence of embodied speech in the spoken transcript. These two figures also demarcate different imagined spheres of circulation (written and oral, print and folklore, intelligentsia and folk) and different forms of authority, what can be called, following Gal and Woolard $(2001,7)$ an "authority of anonymity" and an "authority of authenticity."

These two spheres of textual circulation (print and oral, intelligentsia and peasant) are comparable to the classic "spheres of exchange" in anthropological literature (Kopytoff 1986), in that they are imagined as existing in pure isolation from one another. The anonymous "voice" of the peasant (belonging to the folkloric sphere of a pure oral tradition) can only enter print culture through the translating mediation of the intelligentsia, either by transcription, or as we will see below, through dialogue. At the same time, even as they transcribe the voice of the peasant into the sphere of print culture, the intelligentsia transcribers of folklore devote considerable work to both render the voice of the peasant as a paradoxically anonymous and yet embodied voice, and at the same time purify this voice of any signs of contact with intelligentsia print culture or the differentiated individuality of intelligentsia writers. In so doing, the very act of transcription presupposes the absolute separation of the spheres of circulation that it mediates.

Both of these strategies, of inscription and transcription, importantly, involve the obligatory mediating presence of a writer and help figure the writer's relationship to the rest of the social whole. The pseudonym, we will see, figures the writer in changing relationships to "society," the "public," and the "state." The act of transcription, too, 
requires a writer (a member of "society") to serve as a transcriber for a speaker (a member of "the people"). Therefore, each act of transcription is in itself a figure for changing understandings of the relationship of service between enlightened society and the unenlightened people. In the case of the "Peasant from Kulashi," who, let us remember, is a "temporarily obligated" peasant, that is, one who has received his freedom but is still indentured monetarily to his erstwhile master (Suny $1988,106)$, we can see the seigneurial dependency of the voice of the peasantry on their transcribers, their aristocratic masters (this "temporary dependency" continued in Georgia until virtually the eve of the Russian revolution [Jones 2005, 26]). In the case of the free peasant Lelt Ghunia and Chavchavadze, the transcription figures a new role of post-Emancipation intelligentsia writers in relation to the people, in which transcription becomes a way to close the immense gap between "society" and the "the people," helping the former to "get to know" (gacnoba) the latter, but also becoming a kind of service of the intelligentsia to the people. At the same time, the taste for transcription of the voice of the peasantry reflects the hegemony of the aesthetic of social realism that characterized the movement of "going to the people" in both Russia and Georgia in this period (Paperno 1988, Frierson 1993). At the same time, as we have already seen, transcription of the speaking voice of the people also allowed intelligentsia writers an alternative way to position themselves with respect to the state and their publics.

In the world of performing objects, the pseudonym most resembles a mask, obscuring the natural figure of the self and presenting a staged figure of the theatrical role or persona. In the case of transcription, the writer hides in plain view; there are two figures on the stage, quoter and quoted, like a ventriloquist with a dummy or a puppeteer and his puppets. The orthographic alterations and augmentations forming the technologies of transcription (including not only additional letters but also those diacritics, like accentuation, that do not transcribe semantically distinctive features but seem only to indicate the alterity of the "spoken" qualities of voice to the written word) find their homology in vocal technology like a swazzle to disguise their natural voice. ${ }^{9}$ Using an orthographic version of such a device, writers like Chavchavadze could ground their criticisms in the "authority of authenticity," disavowing any responsibility for the contents of what they transcribe, and at the same time, presenting themselves as humble scribes of the voice of the 
people: "I merely write down what I, as a traveler, heard from him [Lelt Ghunia], in passing."

\section{Pseudonyms: Public Names}

Benedict Anderson's remarkable discussion of the ritual of reading the daily newspaper shows how the semiotic and material properties of the newspaper as print commodity, the simultaneous montage on a single dated page of an unbounded heterogeneity of places and voices, reflect and help mediate the homologous properties of the circulation of this same commodity, particularly the equally simultaneous ritual consumption of the newspaper commodity, so that these two in tandem help produce modern social imaginaries, space-times founded on a sense of contemporaneity. Importantly, Anderson's analysis of the newspaper of print commodity is based on the basic premise that the imaginary it creates is based on a specific kind of imagined reciprocity of perspectives: "almost precisely simultaneous consumption" (Anderson 1991, 35 ), one that is confirmed by day-to-day observation of consociates as well as reciprocities of perspectives with imagined contemporaries: "the newspaper reader, observing exact replicas of his own paper being consumed by his subway, barbershop, or residential neighbors, is continually reassured that the imagined world is visibly rooted in everyday life" (Anderson 1991, 35-6). Anderson seems to take a modern newspaper as his point of reference, where the readers might well imagine a transposability of perspectives, but only with other readers, consumers of the same print commodity.

Warner's influential accounts of publics follows Anderson in focusing on the way the public text constitutes itself by the way it interpellates the reader/consumer, a public "exists by virtue of being addressed" (Warner 2002, 50, I thank Alejandro Paz for making this observation). Publicness is, in this view, constituted by a specific kind of Bakhtinian "addressivity," a "typical conception of the addressee" (in this case as a peculiar unbounded one) which defines it as a genre (Bakhtin 1986, 95). But with Bakhtin, I also want to insist that this "public addressivity" of Droeba depends in part on its responsibility, that is, the way it interpellates an addressee as also a potential respondent, it includes "the possibility of responding to it" (Bakhtin 1986, 76).

A nineteenth-century newspaper like Droeba in general differs from 
the twentieth-century one imagined by Anderson in particular in that there was also a lively perspectival commerce between readers and writers, whose model is the genre of correspondence. Unlike a modern newspaper staffed by professional journalists (where "letters to the editor" form a minor section within the whole), a nineteenth-century newspaper like Droeba is much more likely to be composed more or less entirely of occasional amateur correspondence from the readership, particularly the feuilleton section of the newspaper, forming the lower section of the page, which at least in the Droeba period is composed largely of occasional correspondence. All of Bavreli's correspondence, as well as much of the other material I consider in this book, were placed in this special, heterogeneous section of the newspaper. As we will see in the next chapter, the feuilleton moves from being an exemplary space of heterogeneity within an already heterogeneous whole to being a genre in its own right and these external relations of heterogeneity have become internalized as a constitutive feature of the genre. At the same time, the perspectival dialogues between writers and readers that form the external set of relations of newspaper correspondence become internal relations in the feuilleton, formed as an imagined familiar dialogue between the feuilletonist (who increasingly becomes a pseudonymous "star" or celebrity author) and the readership. But the main contrast to bear in mind is that the public, Georgians, that is, readers of Droeba, were also by and large imagined as potential writers to Droeba-correspondents.

Readers of Droeba entered the public not only by virtue of being addressed, but in part by responding, by writing, by correspondence. How they did this, specifically how they signed their correspondence, in part helped constitute the public they addressed as being of a specific sort. Each different way of signing oneself, what I will call strategies of inscription, produce a different "printed figure" for the writer and projects a different imagining of "society." There are four general strategies of inscription I will discuss: (1) the use of anonymity or pseudonyms to produce a kind of "principle of negativity," which secures the autonomy of the public as a domain of textual circulation from the embodied status attributes of writers; (2) the use of signature using real names or noms de plume to produce a public, which is an extension or augmentation of aristocratic or urban face-to-face publics; (3) the use of pseudonyms as a kind of nom de guerre, protecting the author from state supervision and creating a literary underground; and (4) the use of pseudonyms as a 
kind of cryptonym, a kind of joking or kenning "anti-name" to produce a secret society of a literary bohemia.

\section{The Via Negativa of Democratic Anonymity}

First of all, there is something like a novel sense of "society" as a "public" consisting of liberal strangers in roughly Michael Warner's sense. A writer writing to such a public of fellow writers would write under a pseudonym or pseudonyms, in part to separate the "society" of letters from the "society" of known contemporaries, in particular society in the sense of "urban aristocratic society." Writers of this kind have as their model S. Bavreli, about whom we know nothing more than what they choose to tell us. A pseudonym like Bavreli ("one from Bavra," a very common kind of pseudonym in the Georgian press, to use one's first initial plus a toponymic pseudonym), then plays a number of important roles in creating a specific kind of authorial figure, one specifically involving a moment of anonymity, creating an opposition between the personal embodied properties of a person and the impersonal character of public discourse. The opposition so created echoes a fundamental principle of liberalism that arguments should be evaluated independently of the persons who make them. This rupture between embodied "natural figure" and disembodied "printed figure" (the terms are Goffman's 1974, 523-4), represented by the pseudonym, is captured by Warner under a "principle of negativity" (Warner 1990, 48-9). According to this principle, the autonomy of public discourse is constituted in part by the way that persons are stripped of their embodied status attributes and enter public discourse as an anonymous or pseudonymous voice of a text (Remer 2000, 78-9). Aristotelian appeals to ethos (namely, persuasion based on the properties of the person who makes the argument rather than the properties of the argument itself) are supposedly thereby rendered impossible (Remer 2000, 82). Warner's "principle of negativity" makes anonymity, the rupture between the person and the text, the negation or absence of the person of the author, central to the pragmatics of pseudonymity and constitutive of the publicness of the text.

In Warner's earlier work on publics (1990), this particular kind of anonymity is located within the very specific (American) historical conditions of notions of "republican virtue," a kind of positive ethos that is 
produced precisely by negation of one's private identity (negativity) and by positing an illimitable audience (supervision) produces a sense (ethos, a kind of positive property of the fictive persona) in which the discourse is that of a virtuous public citizen and not a private person, a "voice from nowhere," in effect:

The difference between the private, interested person and the citizen of the public sphere appears both as a condition of political validity and an expression of the character of print. We have already seen that the illimitable readership of print discourse becomes important as the correlative of public supervision; here the apparent absence of a personal author in printed language has become important as the correlative of the principle of negativity ... [A] distinct preference for fictitious personae ... expresses the general principle of negativity in representational politics. (Warner 1990, 43)

Obviously, the pragmatics of pseudonyms ("fictitious personae") cannot, in fact, be entirely reduced to anonymity, the absence of a personal author in printed language (see also Buurma 2007, Coleman 2012, Knuttila 2011, Nozawa 2012 for logics of anonymity often specifically opposed to pseudonymity in different nineteenth-century print and contemporary virtual cultures). For example, a nom de plume, which might well be regarded as a kind of pseudonym, involves assuming an identity as a writer without necessarily entailing anonymity at the same time. As Donath (1998) notes for uncannily similar contemporary use of anonymity and pseudonymity to manage online/offline identity relations:

It is useful to distinguish between pseudonymity and pure anonymity. In the virtual world, many degrees of identification are possible. Full anonymity is one extreme of a continuum that runs from the totally anonymous to the thoroughly named. A pseudonym, though it may be untraceable to a real-world person, may have a well-established reputation in the virtual domain; a pseudonymous message may thus come with a wealth of contextual information about the sender. A 
purely anonymous message, on the other hand, stands alone. (Donath 1998: 21)

Even if anonymity does not exhaust the pragmatic potentiality of pseudonyms, Warner is certainly correct that the pragmatics of most pseudonyms presuppose a foundational moment of anonymity, in the sense of the negation of the embodied, personal author, the production of a stranger. For some authors, it is the anonymity of the pseudonym that allows them to speak in print publics, where they might never speak in face-to-face publics.

Aristocratic Titles and Noms de Plume: The Via Positiva of Aristocratic Society

Competing with this anonymous or pseudonymous sense of "society" as an autonomous public defined entirely by the circulation of texts, as a negation of embodied status, is one in which the society of print is treated as an augmentation or extension of embodied status, specifically an aristocratic or urban "society," a society of known, potentially even famed, consociates (for a parallel opposition between autonomy and augmentation as relations between online and offline worlds, see Boellstorff 2008; for the comparison, see Manning 2009b). Writers from the gentry or nobility, like the princes Ilia Chavchavadze or Akaki Tsereteli, for example, did not need to represent themselves as pseudonymous correspondents from peripheral regions. Usually, they inserted themselves into the "society" in the sense of print public from their position in face-to-face "society" in the aristocratic sense. By signing their own name, often accompanied by their title, they created an intertextual linkage between those two senses of "society," between the spatially localizable, "topical" face-to-face society of the supra, the theater, the opera, the viceroy's court, the city street, and the "metatopical" "society" in the sense of the public of Droeba (for these distinctions see, for example, Warner 2002, Taylor 2002). In the case of service nobles and holy orders, their representative publicity itself prevented them from descending in literary polemics without the use of pseudonyms (Mikadze 1998, 11-13), so that Grigol Orbeliani, the highest-ranking Georgian service noble of the period, used pseudonyms to protect this official representative publicity from the tarnish of his poetic or polemi- 
cal print publicity personae (Mikadze 1998, 12-3).

Nonservice noble aristocratic authors who did not have this sort of conflict of interest might also use pseudonyms, but for them, there would always be a specific stylistic or contextual reason for making use of such a device, having nothing to do specifically with negation of their embodied status. For example, Akaki Tsereteli, the noble who represented and spoke for the "writers" at the supra for the Ottoman Georgian guests of 1878, relatively rarely had recourse to pseudonyms compared even to other nobles like Ilia Chavchavadze (Grishashvili 1987, 8). When he did, he always had specific reasons for doing so. Like many young authors, uncertain of how their works will be received and not wanting to live forever under a "spoiled" literary identity, he used a pseudonym (s_li) for his literary debut in 1858 (Mikadze 1984, 10). On other occasions, when a certain censor named Isarlov forbade him to publish a certain poem, he published it in an out-of-the-way place (Poti, a common gambit) under the pseudonym Luka Isarlov (Mikadze 1984, 22). Since Tsereteli was not a service noble, he did not, like nobles occupying highly public positions within the state apparatus, have to have frequent recourse to a pseudonym in order to publish at all (Mikadze 1984, 12-14).

But most of the time, he would sign his works with some version of his actual name, ranging from his full name and title T. Ak. Tsereteli (in a letter from 1869), where the $T$ stands for tavadi "prince," to just his first name (Akaki in 1875). The first name signature, which he adopts later, so far from being a pseudonym, designed to obscure his identity within a society in which there were many people named Akaki, instead presupposed that his writerly voice was so familiar to his reading public that there was no need for further specification. Like Ilia Chavchavadze, Vazha Pshavela, Galaktion Tabidze, and other well-known writers of the socialist canon, he is referred to by his first name today, even in scholarly works (Mikadze 1984, 29-30). Hence, signature moves from delineating one's position primarily in terms of one's position in terms of status within extra-literary aristocratic "society" (noble title) to one primarily in terms of one's achieved status within literary society (fame, familiarity to the "public"), one's first name becomes, in effect, a nom de plume, and even indexes the tone of familiarity, even intimacy, of the literary world found in the dialogue of the feuilleton. But the basic strategy is one in which the way one signs oneself in the world of the 
press extends or augments, rather than negates, one's embodied personal status attributes.

\section{Cryptonyms: Underground and Bohemian Identities}

While Warner's (1990) influential account of the eighteenth-century republic of letters certainly had no pretense of being a general account of publics everywhere, the categories developed for this singular historical episode, like the principle of negativity, or the idea that publics in general must be self-organized, autonomous from state supervision, can be mistaken for cryptonormative universal categories that publics everywhere must satisfy in order to be properly qualified as publics (for example, in Taylor 2002, Warner 2002). But so far from being a universal attribute of public discourse as such, it appears that some of these categories may have been contested, and partial, ideologies of publicness even within their own historical context. Gary Remer has argued that Warner's "principle of negativity" privileges a specific and interested (antifederalist) ideology of the press, by treating pseudonymy as being essentially a form of anonymity, an attempt to eliminate Aristotelian appeals to ethos, the rhetorical "presence" of the embodied person in their public arguments. By contrast, Remer shows that the competing Federalist ideology, which seeks to use pseudonyms to provide disembodied texts with characterological forms of ethos (e.g., classical pseudonyms redolent of Republican virtue like Agrippa, Atticus, Cato, etc.), or alternatively, to find out the true embodied identities of the authors behind the disembodied texts, were just as prevalent a cultural logic constitutive of the formation of the eighteenth-century American press (Remer 2000, 78-84).

What emerges from this discussion is that the use of pseudonyms (like the features of a public defined by Warner [2002]) can be related to, and must be understood in terms of, different historically specific and politically positioned imaginaries of the public, and we should probably add that there is no real evidence that these social imaginaries have any internal tendencies to move in certain directions; it may be a "long march," but there is no evidence that this long march is going anywhere, and therefore, that anyone is going to "get there" ahead of anyone else, pace Taylor's rather unrepentantly Eurocentric, Hegelian, and normative model of historical progress. While the pragmatic goals to which 
pseudonyms of various kinds can be put, other than merely establishing anonymity, are probably endless and many of them quite generically applicable to many forms of print or virtual culture (and Mikadze [1984] for example devotes no less than twenty pages to listing the possibilities in Georgian tsarist period discourse; see also Grishashvili [1987] and Mikadze [1998] for discussions of the remarkable profusion of forms and functions of Georgian pseudonyms), I wish to argue that there remain certain uses of pseudonyms that index the specificities of the tsarist public sphere as social imaginary. I want to focus on two, the underground pseudonym and the bohemian pseudonym. The use of the pseudonym to constitute a secret discourse among intelligentsia away from state supervision we can collect under the term "underground." The often related use of playful pseudonyms that are sometimes kennings of one's true name (cryptograms or cryptonyms) that creates an esoteric discourse among intelligentsia we can call a "bohemia." Indeed, Ioseb Grishashvili, the Georgian author responsible for creating a folklorized modernist social mythology of "Old Tbilisi" as a "literary Bohemia" (Grishashvili 1963[1927], was also both a prodigious user of pseudonyms [having over one hundred personae] as well as a connoisseur and expert on Georgian cryptograms and pseudonyms [Grishashvili 1969, 1987] (on Old Tbilisi, see Manning 2004, 2009, Manning and Shatirishvili 2011). Both of these are related in a sense as being directly or indirectly by-products (like "Aesopian language" discussed above) of state supervision.

The most striking difference between the kind of "self-organized" Western liberal public that Taylor and Warner take as their ideal and a tsarist public is the normalized existence, in a tsarist public, of state supervision, censors, and repression. That is, these things also exist in Western print publics, but there, they are always treated as a pathological deviation from the normal state of publics, whereas in tsarist and socialist print culture, they are treated as normal, even constitutive, aspects of publicness. This presence of state supervision produces one very obvious difference in the function of pseudonyms, where pseudonyms become, in certain periods, actual secrets, the sphere of circulation they define being called an "underground." Here the pseudonym is not so much addressed to finding a place for the author in a public still dominated by aristocratic society, but addressed to the third party of any public communication, the state, and the censor. The one case where 
we find an aristocratic author like Akaki Tsereteli use a pseudonym, for example, is when he is avoiding a censor, publishing his work under a pseudonym in an out-of-the-way location.

The pseudonym Akakai Tsereteli chooses is the name of the censor himself. This brings us to a second related use of the pseudonym not merely to evade the censor, but as a sort of inside joke at the expense of the censor and those members of the public who are not in on the joke. The intelligentsia self-definition as members of an underground, during periods of state repression in particular, by use of a pseudonym is clear enough, but this same state supervision induces changes in writing and public address that produces a more subtle, related use of pseudonyms to define a kind of "bohemia" at other times. The presence of the censor intervening between the writer and the public means that writing itself will not be quite the same relation to a public as in Warner's example, and neither, consequently, will pseudonyms. Part of the value of the censor is that it constitutes the publicness of writing in a very specific way: the figure of the censors makes the publicness of writing independent of ever actually reaching a public, a self-valuable, heroic, and untrammeled expression of personal creativity, even unrecognized genius. ${ }^{10}$

Such conditions of state supervision give rise to their own characteristic, perhaps pathological, forms of writing (including Aesopian language, for example): one of these, Boym argues, is the social pathology of graphomania: "Graphomania ... is a literary disease, an uncontrollable obsession to write and be a writer" (Boym 1994, 168). Graphomania, which is characterized, among other things, by a "feverish plagiarism, genius-envy, and a sadomasochistic relationship with the reader" (ibid.), is also a form of writing that in a sense is constituted in a relationship with a censor (Boym 1994, 172). The presence of the censor, after all, encourages the writer to think of the act of writing as being a self-sufficient act of self-expression, of "aesthetic emancipation" (Boym 1994, 173), the defiant act of an unrecognized genius. Graphomania also leads to a proliferation of pseudonymous personae: "Graphomania complicates the relationship between author and character, between the author and his multiple personae and pseudonyms, the fictional and semifictional selves that incarnate Romantic geniuses and graphomaniacs" (Boym 1994, 173-4).

As Boym argues, an important symptom of graphomania is the proliferation of pseudonymous personae in writing that is so supervised. Therefore, an important aspect of intelligentsia self-definition is the 
use of pseudonyms as joking personas, producing a set of pseudonyms as decodable anti-names, paralleling Halliday's discussion of subcultural "anti-languages." In the Georgian press, for example, most writers tend to adopt a serious and stable pseudonym as their main authorial persona, by which one creates an intertextual relation of authority, but graphomaniac writers, particularly for humorous or satirical writings, tend to accrete an almost limitless series of alternative joking occasional pseudonyms (Mikadze 1984, 25, Grishashvili 1987, Mikadze 1998), similar to what are called "alts" ("alternate personae") in contemporary online role-playing games (Boellstorff 2008, Manning 2009b). Noted Georgian modernist writer (and folklorist of the urban "Bohemia" of Tbilisi) Ioseb Grishashvili (also a pseudonym) himself used over one hundred pseudonyms (Lortkipanidze 1987, 5-6), many of them variations of (es) (me) ar(a) var "this is not me"-direct metapragmatic statements of nonidentity. Such a profusion of pseudonyms was not unusual, Grishashvili recollected that in the prerevolutionary period

Coworkers at humor publications made use of the most pseudonyms. I. Evdoshvili had ten pseudonyms, Axosp'ireli-15 more, Eshmak'i and Taguna ([Pseudonyms of] N. K'alandadze and Sh. Sharashidze, [respectively] - GM), who knows how many! And that's how it had to be. After 1905, when the reaction got stronger, pseudonyms were necessary (Grishashvili 1987, 8)

Many such pseudonyms are far from being erasures of one's natural figure but are wordplays on the person's actual name. Like the lexicon of an anti-language, these pseudonyms are based on the ordinary name and become puzzles or riddles, cryptograms or cryptonyms in which the natural figure of the author is concealed (Grishashvili 1987). Indeed, many of the same formal processes Halliday identified in the conversion of an ordinary lexicon into an anti-language (Halliday 1976, 576-7) are found in the process of producing cryptonyms out of ordinary names. For example, riddling forms used in anti-languages often involve simple inversion of sounds or letters, and this is true too of cryptonyms as play forms (Mikadze 1984, 28-9, Mikadze 1998, 22-25): whole name, e.g., Aleksandre Toidze-A. Edziot (1888, dz is a single letter in Georgian); Ivane Tsilosani-Enavi Inasolits (1914); of part of the name, 
the folklorist Tedo Razikashvili (Vazha Pshavela's brother)-R. Odet (1905); Mose Janashvili-Esom (1886-1896), as well as other kinds of kennings, virtually every imaginable variation from simple initials, to simple initials spelled out using the names of characters as in the Russian or Georgian alphabet (examples 1-2 below ), to various other formal operations of substitution and deletion of the beginning, end or middle of the name (examples 3-4 below), were possible. Additional variations were made possible by using a Latin alphabet or indicating the initials using a numerological puzzle ("904" indicates the initials "Sh. D." [Shalva Dadiani] because conventionally the 900 is the numerical value of the letter $S$ and 4 is the value of the letter $D$ in the Georgian alphabet [Mikadze 1984, 45]).

An excellent example of the coincidence of pseudonymy as play language and actual play languages is given by the example of a certain Samson Qipiani, who, in weekly feuilleton entitled "A Letter from Witchland" (Cerili Kudianetidam) appropriately disguised his first name using a playful children's anti-language called kajuri (named after a kind of sprite, a kaji [on which, see chapter 7] who is noted for doing everything backwards). In kajuri, one inserts a syllabified consonant, either $\left[t s^{\prime}\right]$ or as here $[p]$ after every open syllable ( $\mathrm{CV}$ becomes $\mathrm{CV} p \mathrm{~V}$, where $C$ stands for a consonant and $V$ for a vowel) or after every nasal in the syllable coda (CVN becomes $C V p V N p$, where $N$ is a nasal $[m, n])$. Hence, Samsoni ("Samson") becomes sapampsoponipi ( $\mathrm{Sa}(\mathrm{pa}) \mathrm{m}(\mathrm{p})$ so(po)ni(pi)) (example 5 below).

\section{Examples}

\section{Name}

(1) Mixeil Bebutashvili

(2) Ilia Peradze

(3) Andro Dolidze

(4) K'ondrat'i Gvasalia

(5) Samson Qipiani
Pseudonym

embe

in da pari

doli

alia

Sapampsoponipi
Process

initials $\mathrm{M} \mathrm{B}$ as prounounced in Russian initials pronounced in Georgan plus "and"

doli (dze)

(gvas) alia

Sa(pa)m(p)so(po)ni(pi)
Source

Droeba 1881

Iveria 1895

Mogzauri 1910

Cnobis Purceli 1898

Iveria 1887 (p. 34) 
The list of formal operations attested almost exhausts the logical formal possibilities. The point is that these are not secrets any more than "Pig Latin" or kajuri are viable secret codes; they are riddles, puzzles, playful inside jokes that, like Aesopian discourse, separate those who know from those who don't, those can solve them and those who can't, or simply reflexively index by their form their own playful intent (cf., Mikadze 1984, 46). As Halliday argues with respect to anti-languages, the very "looking glass form" of anti-languages as inversions of normal language produces an indexical icon of anti-societies that view themselves as inversions of normal society. The anti-language, then, is not merely a referential "set" (to secrecy, hiding the meaning of everyday words by inverting their form, appropriate to avoid state supervision), nor yet a "set" to the form of language (verbal art, poetics, verbal play, play languages, exemplifying the sheer fun of making up new antiwords and kennings and testing creativity), but indeed is an image of the social totality that produces them, a "set" to the social totality (Halliday 1976). In effect, adopting a pseudonym expresses a writer's intention to address a public, a cryptonym serves to divide this public into an exoteric public including both the censor and ordinary people, and a bohemian counter public, a urban literary bohemia (Grishashvili 1963 [1927]) which is akin to Halliday's "anti-society" of criminals (and in later Georgian urban life, these two would merge; see Manning 2009c). The riddling quality of these names could hardly serve functions of secrecy, but they do produce a kind of esoteric discourse within public discourse, in which members of the aristocratic/intelligentsia "society" could recognize each other's playful selves. Writers like Warner are fascinated by the potentially limitless, indeed infinite, potential reach of public address: "The meaning of public utterance . . . is established by the very fact that their exchange can be read and participated in by any number of unknown and in principle unknowable others" (Warner 1990, 40-1). But it must be remembered how very finite, even microscopic, Georgian print culture was and is, compared, for example, to its defining model, Russian print culture or French print culture, and how self-aware it was of this finitude.

In fact, this very sense of finitude is also registered in the use of pseudonyms. To produce a sense of an infinite public address of limitless strangers in the cramped world of known contemporaries, Georgian print culture resorted to the semiotic technology of the pseudonym. 
Pseudonyms could serve to give an impression of wider boundaries or greater population to this imagined print culture than actually existed. A prolific single author, or an editor who wishes his journal to appear to have many contributors, might write many articles under different names to produce a sense of a broad base of correspondence and diversity of perspectives (Mikadze 1984, 10). Writers' circles like the Georgian bohemian poets of the 1920s wished that their circle could have contained a woman poet, but, alas, they knew no women poets, so Paolo Iashvili made one up and wrote poems under her name (Mikadze 1984, 11). In fact, if women writers occasionally made use of male pseudonyms to overcome the difficulties of reception their gender presented them as writers (Mikadze 1998, 13), an even larger number of Georgian men wrote under female pseudonyms for various reasons (Grishashvili 1987, 13).

The sense that Georgian print culture was not only finite, but anything but cosmopolitan also played a role in pseudonymy. Writers especially of non-Georgian origin might wish to present themselves via pseudonym as Georgian, this part of a more common process that included proper names and surnames as well (Beglar Aghamov as Beglar Axosp'ireli, Bughdan Evangulov as B. Davitashvili, etc. [Mikadze 1984, 15]). At the same time, writers wishing to produce a sense of cosmopolitan alterity and authority within such a small, perhaps stiflingly small, national print discourse, might instead posit themselves as a voice of Russian or European origin, sometimes rendered in a Cyrillic or Latin alphabet, as appropriate, connecting the author's voice with international or cosmopolitan political programs (Mikadze 1984, 16). Such Occidentalizing tendencies could be matched by a rarer Orientalizing tendency restricted to bohemian authors of the 1910s-1920s, who sometimes adopted pseudonyms of "Oriental" origins (Mikadze 1984, 16-17) (Ioseb Imedashvili-Ali Oghli [1913], Ioseb Grishashvili-Rashid Vardanoghli [1923], Davit K'asradze-Ali Azizi [in Batumi newspapers], and so on).

Under such circumstances, too, these others were never "in principle unknowable," and the guesswork of trying to locate the real person behind the pseudonym in closely linked networks of known social others in a small country and even smaller urban intelligentsia society could easily become a game of mutual self-recognition. Georgian literature was born, as Chavchavadze argues "shinaurobashi," among closed circles of intimates: producing a public of strangers out of this familiar discourse 
between intimates required a certain work of estrangement (as Warner puts it [2002, 81]), perhaps a greater work than we suppose, pseudonyms on this level were an important technology of estrangement, working to produce an infinite "universe" of stranger contemporaries (Mikadze's [1998] book is after all titled In the Universe of Georgian Pseudonyms) out of an extremely finite "village" of known consociates. At the same time, this public of strangers, which is always already divided between an exoteric public discourse and an esoteric bohemian discourse, always verges on recreating a literature shinaurobashi ('domestic, between intimates') on a new level, precisely this tendency is indexed by the use of kenning cryptonyms, and later, by the "intimate stranger" voicing of the urban feuilleton. It is a form of elitist, esoteric, bohemian social closure very like the social closure of aristocratic networks within print culture, very different from the principle of "supervisory publicness" in a Western republic of letters. More characteristic of a later, already self-aware and self-obsessed intelligentsia of the late 1890s and early twentieth century, this understanding opposes the avant-garde intelligentsia as underground to the state, and as urban bohemia to the rural people. But most of all, we see from the pseudonymy of the graphomaniac and the celebrity writer, especially the serialized feuilletonist, all of whom "branded" their popular weekly columns by the use of pseudonyms, that if pseudonyms strip the author of their old, embodied identity, this is not merely a shedding of an old identity; it is an act of rebaptism that transforms a mere scribbler into a well-known writer. To be a writer, then, is defined first and foremost by having at least one, and perhaps many, pseudonyms. As with monastics and soviet mafia, to enter this world, one must be rebaptized as a stranger.

\section{Transcribing the People}

If the creation of a liberal public required an act of "unknowing," turning a finite list of known urban contemporaries into an infinite universe of strangers, the intelligentsia's relation with the people was figured by the opposite imperative of "getting to know" the strange people and lands of rural Georgia. In the wake of emancipation in Georgia, as in Russia, the perception of a vast gulf between the unenlightened "people" and enlightened "society" occasioned a "sense of moral responsibility and guilt toward, and a perception of a dreadful separation from, the vast 
majority of the population. . . Most of the authors who went to the countryside were seeking redemption through rapprochement with the peasantry" (Frierson 1993, 9). For Georgians, in the post-Emancipation period of the 1860s up to the Russo-Ottoman War (1877-8), it seemed imperative that members of society should become reacquainted with, "get to know" (gacnoba), the people. In the wake of the Russian victories and the capture of Ottoman Georgia, this motive would be displaced from the people of European Georgia to the even more estranged people of Ottoman Georgia.

"Getting to know" the people would not only involve the traversing the vast social divide between oral and literate cultures of the unenlightened "people" and enlightened "society," but it would also involve concrete movement in space, because the peasantry mostly lived in villages, and "society" now lived primarily in cities. Luckily, however, unlike Russian "society" who perhaps had to travel some great distance to the countryside, perhaps to a village they had never seen before, in the case of Georgian society, the distance to be traversed to get to know the people was short, and it was an excursion they made from the city every summer in any case:

Summer has come and the society (sazogadoeba) of our cities is going out to the village. How many could have gained much utility along with pleasure! Whoever has learning and a sharp mind, how much bad and good would he observe in the village, how much that is new would he become aware of and see, he would get to know [gacnoba] the life of the people! ${ }^{11}$

So begins the inaugural in 1871 call for the collection of folklore by correspondence in the pages of Droeba. The author, Petre Umikashvili, argues that the annual return of urban society to the village is more than an opportunity to escape the stifling heat of the city and rest, but it is also an opportunity to "get to know" the people; for example, by the collection of folkloric materials, materials for creation of a specifically Georgian print culture, published books of folklore. This already-existing form of yearly urban-rural transhumancy is for Umikashvili not only an opportunity for the collection of oral materials from among the people to be published, it is also a moment in which these published materials, 
in the form of printed books, can be returned to the people. Hence, his answer to the question, "How must we spread Georgian books among the people?" published the next year is envisioned as happening in precisely parallel terms:

Lo, summer has come and now all of us are spreading ourselves out here and there in villages and cities: couldn't we writers get books on credit and take them to villages to sell among our relatives? . . Taking this matter forward is something we all can do, whoever we are, whether we live part time in the village, or permanently. ${ }^{12}$

Circulation of texts, in a country as small as Georgia, far from being imagined as being infinite or limitless, is in fact imagined as being much of a piece with the embodied circulation of the writers themselves. In fact, the yearly circulation of urban society among the rural people is precisely the motor that drives the circulation of texts, it is the mechanism by which the voice of the rural people can enter the urban public world of print discourse (via folkloric transcription), so that the public can get to know the people, and it is also the mechanism by which printed texts, and literacy more generally, can be propagated among the people, so that the people can become a public.

The project is to "get to know" (gacnoba) the people, and Umikashvili suggests that the best way to get to know the people is by transcription, that is, by collecting "folk stories, songs, shairi, tales, riddles, charms, proverbs," because "the people's beliefs, thoughts, suffering, happiness, hope-are expressed and dispersed in the poems and stories of the people." ${ }^{13} \mathrm{He}$ argues not only that this is easy to do, it is something that, for example, students could do, "because they all live in villages in the summer anyway and have lots of free time, too"; ${ }^{14}$ it is also something that Georgians should do, because the "living words of the people" form better materials for the work of historians than "rotten, ancient tomes." Furthermore, there is the existing example that "in Europe distinguished and famous writers have gone from village to village, have written and published" and in Russia too since $1815 .{ }^{15}$

Transcription, I have argued, occurs in and mediates not only a social imaginary divided between an illiterate people and a literate society and 
their corresponding spheres of textual circulation, but also an imaginative geography divided between a people rooted in the village and a mobile society that circulates between the city and the village. The voice to be transcribed is defined in terms of these categories, and the theory of transcription both presupposes and polices the boundaries of these categories: one must transcribe "generally what the people ( $x a l x i)$, that is the peasant people (glexi xalxi), the people of the village (soplis xalxi), sing." Transcription will turn this pure stream of oral folk circulation into written correspondence, bring the voice of the people into the public, and eventually bring it back to the same people as part of a campaign to spread literacy. But in the moment of transcription itself the stream of folk, oral speech must be kept pure and segregated from the stream of print circulation, of writers and urban people. Umikashvili's methodological strictures are particularly concerned with establishing the folkloric pedigrees of texts and avoiding hybrids, something he regards to be particularly important "in this period of mixed up language" (enis areul-dareuloba).$^{16} \mathrm{He}$ complains that up until now, only a handful of authentic folkloric texts have been published, and existing chrestomathies mix up "folk" ("peasant, village") with "city" songs, which are either "compositions of some writer" (as opposed to the "people" who presumably represent an anonymous, collective author which does not "write" but "sings") or represent the work of an urban guild worker (not "a peasant"), and in general circulate only in the social milieu of the city. ${ }^{17}$

Here, in the specification of what constitutes "the people," we see a series of exclusions that seek to constitute the folk and the folk sphere of circulation as being the diametric opposite of the sphere of circulation of the transcriber, a metapragmatic specification of kinds of author, the authorial identity of the transcriber and the transcribed, the intelligentsia society and the people, which is constituted in transcription (transcriber, transcribed) and in correspondence (city, village). The author of intelligentsia urban print culture is an individual who writes with a pseudonymous signature; the speaker of rural folk culture is collective and speaks anonymously.

Such a definition of the parameters of "folk" (xalxuri) circulation becomes standard for Georgian folklore throughout the socialist period. The twentieth-century linguist and folklorist Akaki Shanidze, cofounder of Tbilisi State University and of the academic discipline of Kartvelology, including Georgian philology and folklore studies (on 
whom, see Cherchi and Manning 2002) in general followed Umikashvili and his European predecessors in defining folklore as a mode of textual circulation that differed in every respect from print culture, from authorship to mode of circulation to kind of public. The only difference between Umikashvili writing in 1871 and Shanidze writing in 1931 is that, following the October Revolution, the rural peasantry is also considered to be proletarian. Since the mode of transmission is communal and the poetry is mutable, questions of attribution and authorship are irrelevant: ${ }^{18}$

When I say "folk poetry", I mean such poetry as was born, developed and circulates among the working people of the village, among the peasantry, in that social circle, which is at work and labor and mostly ignorant of reading and writing. This is that poetry, which spreads usually by oral transmission from one man to another and from the older generation to the younger. Its preserver and defender is the memory of many persons and this is the reason that its form and content is mutable. . . . (Shanidze 1931, 5)

Purism of pedigree of this authentic voice must be attended by purity of form, preserved by a strict proceduralism in transcription. Umikashvili is quite strict (both to the writer and the peasant): "You must make the peasant say, and you must write it completely, thus unchanged, as the peasant says it: not one letter must be changed" [emphasis added]. ${ }^{19}$ Umikashvili allows that this method is really only applicable to poems, which can be transcribed by line-by-line repetition; stories, by contrast, have to be gotten in one take, and in effect, recomposed rather than transcribed. Here Umikashvili simply allows that "after hearing the whole thing once you can write it, you should, of course, preserve the language of the people, the proper names and whatever poems there are here and there within in." 20

Not merely must the transcription preserve the distinctive form of the speech of the peasant, using devices like special supplements to the orthography or footnotes (2-3), but peasant speech is always contextualized in an itemized list of indexical features of context that must accompany the transcription $(1,4-6)$, including features that pay special 
attention to the changes the text undergoes in the process of circulation (1), or which seek to identify whether the source of the poem is in fact "folk" (saxalxo) or whether it entered folk circulation from books or from the repertoires of minstrels (4-5). In all these considerations, maintaining a pure, unmixed pedigree of the oral text from the moment of oral composition $(1,4-6)$ to the moment of written transcription (1-3) is paramount to segregate authentic examples of "folk" (saxalxo) circulation from other parallel forms of circulation, written or oral, but also constitutes folk circulation as being about form, rather than referential content, a matter of performances, rather than circulating texts. It emerges that that oral circulation of texts is the very antithesis of print circulation.

(1) Repetition: While the technology of print propagates printed texts as identical copies, oral texts are ever changing in the process of circulation, losing or gaining a word or two there, or otherwise changing their form, hence "However many times a man encounters one and the same song, poem, fairytale, he must write it down."

(2) Form: "every letter (aso) must be written as the peasant pronounces it," a formal device which separates the spoken transcription from the written text, in particular, by expanding the kinds of letters which are used in transcriptions beyond those used normally.

(3) Footnotes: "The meaning of words that the transcriber does not understand, he should ask and make for them a footnote," a device we have seen with both Chavchavadze and others; the footnote in particular establishes a hierarchical relationship between the order of transcribed voice and the order of the commentator, in a manner homologous to the way the editorial footnote subsumes and subordinates the text of the writer.

While these features attend to the form of the text, the next features attend more to locating the text within a field of circulation and performance, again with a view to ensuring that it belongs to a sphere of "folk" (saxalxo) circulation. (4) Place: "In what village did the transcription occur, from what village did the speaker learn it, or did he learn it at the house of a lord?" This latter question is important, because such poems are not folk, if they were "learnt from books in the house of the master." Nowhere does Umikashvili ask that we write down the name of the speaker, all one needs to know is where, not who, because the folk author is anonymous and collective. (5) Source: Just as Christian 
prayers become "folk" to the extent that they have been refashioned in some way, so too the repertoires of traveling minstrels can eventually enter the folk repertoire, become folk (saxalxo) "in the end." But until this happens, a sharp demarcation of minstrel's works and folk works must be maintained, just as the repertoire of the city must not be mixed up with that of the village: always ask with respect to any work whether "that poem (leksi) was composed or not by the speaker, or heard from a minstrel or from a peasant." (6) Contexts of performance: "Always ask what context each poem is sung in, which ones are sung working," and so on. (7) Lastly, for those poems written in languages or dialects that are unintelligible to a Georgian (Mingrelian, Svan, Ingilo), a Georgian translation must be provided. ${ }^{21}$

In a penetrating analysis of different ideologies of transcription that inform discourses of language endangerment and preservation, Robert Moore (2006) has recently noted the way that writing is positioned as mediating across an almost metaphysical divide between oblivion and status as a "language": "[T]he act of writing [is situated] precisely astraddle that line, endowing writing with the power to move (a) language, word by painstakingly transcribed word, from one side of that metaphysical divide to the other." Certainly Georgian folklorists like Umikashvili saw in the act of transcription a power to mediate metaphysically the divide between these two spheres of circulation, but transcription also constituted and policed the boundaries of the spheres of circulation it mediated.

The objective of transcription is to reduce a living text "as if in amber," but at the same time, an attempt to animate an inanimate written text, to confer qualities of life and movement, of living speech, to something that must now circulate under the conditions of print culture. Seeking to mediate a metaphysical divide between living speech and print, transcription reproduces the difference in a new form. The order of transcription implies an ontological opposition between embodied peasant speech, which is always laden with a surplus of form beyond what can be transcribed, and is always contextualized by surplus of indexicality when compared with the disembodied, decontextualized writing of intelligentsia, which, propagated in self-identical form in print, is always entextualized, maximally independent from context. The speech of the peasant is not only distinctive and different in its embodied form, which must somehow be conveyed in writing, but while circulation of a 
newspaper like Droeba is unbounded in space and time, peasant circulation is ever changing and always shot through with indexical relations to its context. Writerly works are sharply entextualized texts, that is, formally, sharply bounded, decontextualized texts, able to be circulated in more or less the same form on the pages of Droeba, peasant speech is always part of a local, highly contextualized hic et nunc, performance (for these distinctions see for example Bauman 2004). The speech of the folk becomes writing through the service of the writer, and hence, the voice of the folk, like Lelt Ghunia, is always in quotation marks. 